\title{
Plexiform Neurofibromatosis Involving Face and Oral Cavity: Report of Two Cases and Surgical Challenge
}

\section{Faryabi J and Mehrabizadeh $\mathrm{H}^{*}$}

Department of Oral and Maxillofacial Surgery, Kerman Medical University, Iran

*Corresponding author: Hoda Mehrabizadeh, Department of Oral and Maxillofacial Surgery, Kerman Medical University, Shafa st Dentistry School, Iran

Received: May 06, 2017; Accepted: June 07, 2017; Published: June 22, 2017

\begin{abstract}
Plexiform neurofibromas represent an uncommon variant $(30 \%)$ of neurofibromatosis type 1 (NF-1) in which neurofibromas arise from multiple nerves as bulging and deforming masses involving also connective tissue and skin folds. progressive facial deformity that began in early childhood. Skin examination also revealed multiple neurofibromas and cafe'-au-lait macules on the trunk and arms. Histopathological examination on biopsy samples showed overgrowth of peripheral nerve components and connective tissue. Diagnosis of plexiform neurofibromas is usually made clinically, especially if classical hallmarks of NF-1 are present. Therapy is surgical, aiming at resecting deforming masses. We present two cases of facial neurofibromatosis managed in our hospital. The first patient presented with overhanging mass of skin folds on the right side of her face, completely obliterating her right eye. The other patient was a young male having a unsightly swelling over the right cheek. Physical examination revealed the presence of café au lait macules, freckling in the axillary region. Reconstructive surgical procedure in the form of subtotal excision of tumor mass followed by re draping of the facial skin was performed in both cases. There was evidence of regrowth of the tumor on review after 6 months.
\end{abstract}

Keywords: Facial plexiform neurofibromatosis; Regrowth; Café- au- lait macules

\section{Introduction}

Neurofibromatosis type 1 (NF-1) is a rare autosomal dominant genetic condition (1/3000 subjects), and a poorly defined benign tumor of the peripheral nerve sheath that caused by mutations of the NF1 gene, which is located at chromosome. 17q11.2, characterized by multiple skin alterations such as cafe-au-lait macules and axillary freckling and by tumoral growth along nerves, called neurofibromas $[1,2]$. Plexiform neurofibromas represent an uncommon variant of NF-1 in which neurofibromas arise from multiple nerves as bulging and deforming masses involving also connective tissue and skin foldshence the clinical description of lesions as "bags of worms . Facial plexiform neurofibroma may produce various degrees of cosmetic and functional deformities in the head and neck region [3]. We present two such cases managed in our hospital and discuss clinical findings, diagnosis, and therapy of this rare deforming disorder.

\section{Case Presentation}

\section{Case 1}

A 17-year-old girl was referred for evaluation of a progressive facial deformity that began in early childhood (at around 2 years of age). Her medical history was unremarkable and none of the relatives was known to be affected. On physical examination the right side of her face was deformed by a bulging and soft mass involving the eyelids, cheek, and nose; also the lips and chin were affected, with sparing of the forehead (Figure 1). The patient was unable to open his right eye due to overhanging folds involving the eyelids. However, the mass did not result in vision impairment or speech difficulties.

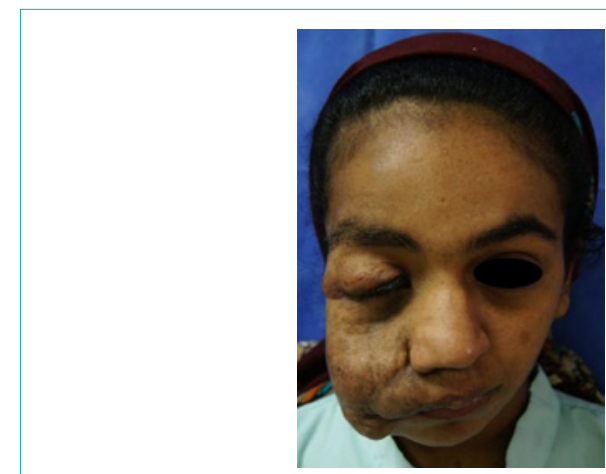

Figure 1:

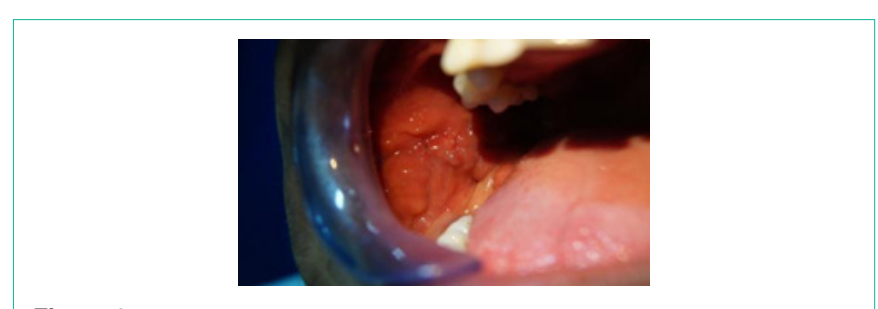

Figure 2:

Skin examination also revealed multiple neurofibromas and cafe' -aulait macules on the trunk and arm). Laboratory tests were normal. Histopathological examination on biopsy samples showed overgrowth of peripheral nerve components and connective tissue .Craniofacial MRI confirmed the presence of a deforming mass arising from the
Austin J Dent - Volume 4 Issue 5 - 2017

ISSN : 2381-9189 | www.austinpublishing group.com

Mehrabizadeh et al. (C) All rights are reserved
Citation: Faryabi J and Mehrabizadeh H. Plexiform Neurofibromatosis Involving Face and Oral Cavity: Report of Two Cases and Surgical Challenge. Austin J Dent. 2017; 4(5): 1083 


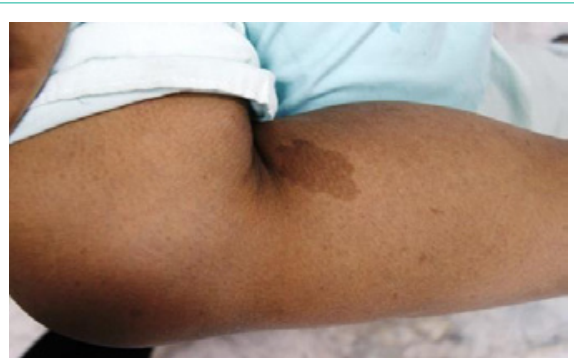

Figure 3:

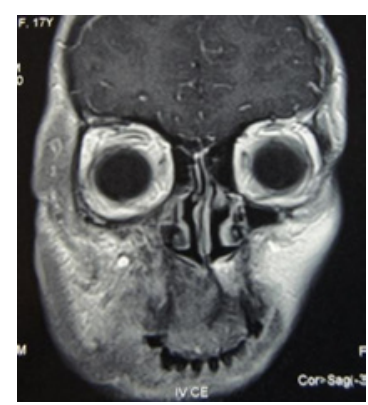

Figure 4:

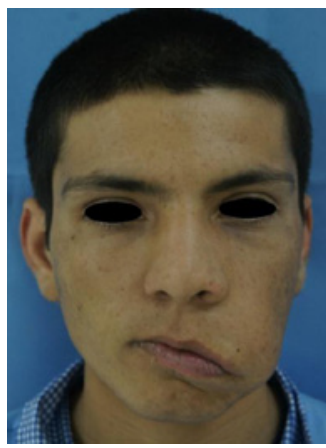

Figure 5:

right side of her face giving homolateral eye dislocation (Figure 2,3 and 4).

\section{Case 2}

18-year-old boy was brought to our out hospital with a history of progressively increasing swelling over the right side of his face since childhood.

Physical examination revealed a huge soft tissue swelling involving the right mandibular region and cheek pulling down the right angle of the, He had few axillary freckles and café au lait macules over his back (Figure 5,6 and7).

Both patients taken up for reconstructive surgery and the swelling were approached through pre-auricular incision extending superiorly into the temporal area. Tumescent fluid infiltration was carried out in the tumor mass to reduce the blood loss. The tumor mass was infiltrating deeply and the tissue planes could not be defined. There was gross thickening of facial nerve in the pre-auricular region as well as its branches. Subtotal excision of tumor mass and readjustment of facial flap was carried out with reasonable post-op correction

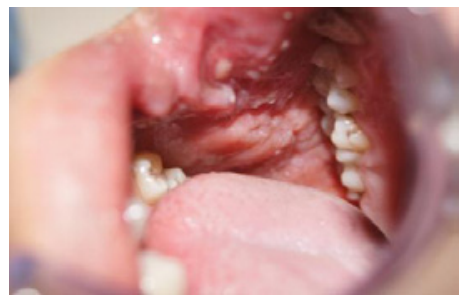

Figure 6:

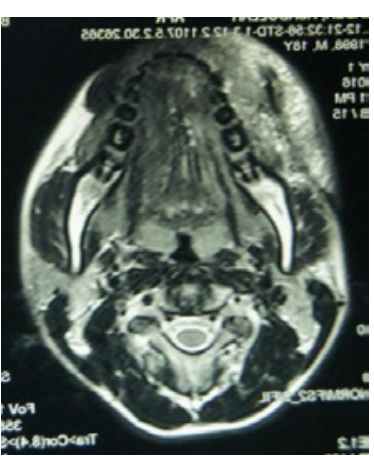

Figure 7:

However, 6-monthly review in both case well showed evidence of some regrowth.

\section{Discussion}

PNF is a rare type of generalized neurofibromatosis, which occurs duetoovergrowth of neural tissuein the subcutaneoustissue. The diffuse and soft nature of PNF is often compared with "a bag of worms [4].

The lesions can occur anywhere along a nerve, and may appear on the face [4], orbit and globe [5], and frequently involve the cranial and upper cervical nerves [6]. The condition can be quite disfiguring, as observed in the cases being presented, and hemifacial hypertrophy can occur [7]. Complications include bleeding from trauma, neurological deficits and psychological disturbance because of abnormal anatomy [4].

Histologically, these are peripheral nerve sheath tumors containing all elements of the peripheral nerve, and are characterized by an increase in endo-neural matrix with separation of nerve fascicles and proliferation of Schwann cells [6]. PNF can turn malignant in $4-5 \%$ of cases [7].

Resection and debulking of invasive PNF is however associated with a high rate of recurrence. In one pediatric series, complete resections developed recurrence in $20 \%$ and incomplete resections had a recurrence in up to $45 \%$ of the cases [4]. One of the limiting factors is vascularity of these lesions and their abnormal propensity to bleed. These tumors bleed profusely during surgery because of the friable nature of the neo-vessels. Adequate blood should be arranged before taking up these cases for resection.

Surgical management remains the mainstay of treatment for these tumors, but functional disturbances are almost inevitable while resecting tumors involving the head and neck region. No chemotherapeutic agent has yet been identified that reduces the size 
of these tumors [8].

\section{References}

1. Evans DG, Howard E, Giblin C, Clancy T, Spencer H, Huson SM. Birth incidence and prevalence of tumor-prone syndromes: estimates from a UK family genetic register service. Am J Med Genet A. 2010; 152A: 327-332.

2. Friedrich RE, Schmelzle R, Hartmann M, Fünsterer C, Mautner VF. Resection of small plexiform neurofibromas in neurofibromatosis type 1 children. World J Surg Oncol. 2005; 3: 3-6.

3. Needle MN, Cnaan A, Dattilo J, Chatten J, Phillips PC, Shochat S, et al Prognostic signs in the surgical management of plexiform neurofibroma: The Children's Hospital of Philadelp hia experience, 1974-1994. J Pediatr. 1997; 131: 678-82.

4. Patil K, Mahima VG, Shetty SK, Lahari K. Facial plexiform neurofibroma in a child with neurofibromatosis type I: A case report. J Indian Soc Pedod Prev
Dent. 2007; $25: 30-35$

5. Arute JE, Nwosu Paul JC, ErahPatrick O. Facial Plexiform Neurofibromatosis in a 16- year Old Female from Eastern Nigeria: A Rare Presentation. Int J Health Res. 2008; 1: 105-110.

6. Ferrozzi F, Zuccoli G, Bacchini E, Piazza P, Sigorini M, Virdis R. Extracerebra neoplastic manifestations in neurofibromatosis 1: Integrated diagnostic imaging. Radiol Med (Torino) 1998; 96: 562-569.

7. Ducatman BS, Scheithauer BW, Piepgras DG, Reiman HM, Istrup DM. Malignant peripheral nerve sheath tumors. Cancer. 1986; 57: 2006-2021.

8. Mukherji MM. Giant neurofibroma of the head and neck. Plast Recon Surg. 1974; 53: 184-189.
Austin J Dent - Volume 4 Issue 5 - 2017

ISSN : 2381-9189| www.austinpublishinggroup.con

Mehrabizadeh et al. ( ) All rights are reserved
Citation: Faryabi J and Mehrabizadeh $\mathrm{H}$. Plexiform Neurofibromatosis Involving Face and Oral Cavity: Report of Two Cases and Surgical Challenge. Austin J Dent. 2017; 4(5): 1083 